\section{Physical inactivity in developing countries}

Lear and colleagues ${ }^{1}$ observed much stronger relationships between the ownership of household devices and obesity and diabetes in adults from low-income countries compared with those from high- and middle-income countries.

Although these devices were relatively uncommon among participants from low-income countries, ownership may increase with rapid economic development. This transition may have dire consequences for the health systems of low-income countries, which are already struggling with a high prevalence of infectious diseases ${ }^{2}$ and road traffic injuries. ${ }^{3}$

Evidence suggests that the majority of youth and adults in low-income countries fail to meet current physical activity guidelines. ${ }^{4}$ In sub-Saharan Africa, higher socioeconomic status and living in an urban area were associated with greater engagement in sedentary behaviours (including screen time) among children and youth. ${ }^{5}$ Even more surprising are the relatively low rates of active transportation to and from school observed in population-based samples of youth in many low-income countries in Africa. ${ }^{6,7}$ This suggests that although privately owned cars are relatively scarce in these countries, other forms of motorized travel are routinely used by a large proportion of inhabitants.

The findings of Lear and colleagues ${ }^{1}$ underscore the importance of promoting an active lifestyle in low-income countries. The United Nations' political declaration on noncommunicable diseases $^{8}$ is a good step in the right direction, but there remains a clear need for raising the political priority for developing and implementing effective and culturally relevant interventions to prevent noncommunicable diseases in low-income countries. ${ }^{9}$

\section{Richard Larouche PhD}

Postdoctoral fellow, Children's Hospital of Eastern Ontario Research Institute, Ottawa, Ont.

\section{References}

1. Lear SA, Teo K, Gasevic D, et al. The association between ownership of common household devices and obesity and diabetes in high, middle and low income countries. CMAJ 2014;186:258-66.

2. Lozano R, Naghavi M, Foreman K, et al. Global and regional mortality for 235 causes of death for 20 age groups in 1990 and 2010: a systematic analysis for the Global Burden of Disease Study 2010 [published erratum in Lancet 2013;381:628]. Lancet 2012;380:2095-128.

3. Global status report on road safety 2013. Geneva (Switzerland): World Health Organization; 2013.

4. Hallal PC, Andersen LB, Bull FC, et al. Physical activity levels of the world population: surveillance progress, gaps and prospects. Lancet 2012;380: 247-57.

5. Muthuri SK, Wachira LJ, Leblanc AG, et al. Temporal trends and correlates of physical activity, sedentary behaviour, and physical fitness among school-aged children in Sub-Saharan Africa: a systematic review. Int J Environ Res Public Health 2014;11:3327-59.

6. Guthold R, Cowan MJ, Autenrieth CS, et al. Physical activity and sedentary behavior among schoolchildren: a 34-country comparison. J Pediatr 2010;157:43-9.

7. Peltzer K. Health behavior and protective factors among school children in four African countries. Int J Behav Med 2009;16:172-80.

8. Political Declaration of the High-level Meeting of the General Assembly on the Prevention and Control of Non-communicable Diseases (2011 Sept. 19). New York: United Nations; 2012. Available: http://daccess-ods.un.org/TMP/7667779.92248535 .html (acecssed 2014 Apr. 4).

9. Geneau R, Stuckler D, Stachenko S, et al. Raising the priority of preventing chronic diseases: a political process. Lancet 2010;376:1689-98.

CMAJ 2014. DOI:10.1503/cmaj.114-0071

\section{Not all patients are the same}

Yes, it is time to embrace transparency (long overdue actually)! I've worked in the health care industry since 1982 , mainly in the field of health information management, and mostly in acute care hospitals. Over the years, I've had the pleasure of meeting many patients who have a legitimate need to access their personal health information.
These patients aren't necessarily the younger generation either. They come from all demographics. They are curious, and they have a vested interest in understanding more about their medical conditions - more than can be gleaned from the brief 10 minutes their general practitioner can give them. These people are more interested in understanding what their laboratory values mean (in layperson's terms) than what some nurse or doctor said about them in their record.

I have a few health conditions (comes with being in my fifties) and I too, have had to face the hassle of getting access to my personal health information and laboratory work. The privacy rules and nonsense that I have had to endure are so antiquated that I can only imagine the level of frustration the average patient feels.

It's time to change. Not all patients are the same. Some, like me, actually understand medical terminology and its myriad acronyms.

I could care less what some nurse or doctor writes about me. I just want the data, the test results, the evidence. I just want simple, easy access to my own personal health information, when I want it, where I want it and how I want it. It's my information. It's about me. So, what's the hold up?

\section{Sheri McMann CHIM}

Health information management practitioner, Five Hills Health Region, Moose Jaw, Sask.

\section{Reference}

1. Patrick K. Patients and their medical records: it is time to embrace transparency. CMAJ 2014;186:811.

CMAJ 2014. DOI:10.1503/cmaj.114-0072

\title{
Correction
}

\section{Omission from a contributors statement}

A research article that appeared in the Mar. 3, 2014, issue of CMAJ contains an error. The statement, "Vincent Y.F. Su and C.J. Liu contributed equally to this manuscript" was omitted from the contributors statement. CMAJ apologizes for this omission.

\section{Reference}

1. Su VY, Liu CJ, Wang HK et al. Sleep apnea and risk of pneumonia: a nationwide population-based study CMAJ. 2014;186:415-21.

CMAJ 2014. DOI:10.1503/cmaj.114-0073 